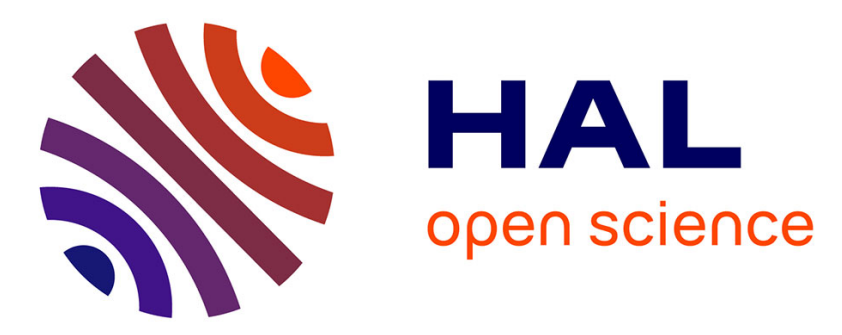

\title{
Mechanical properties of graphene nanoplatelets reinforced epikote 828 under dynamic compression
}

Sabrine Khammassi, Mostapha Tarfaoui, Yumna Qureshi, Hamza Ben Yahia

\section{To cite this version:}

Sabrine Khammassi, Mostapha Tarfaoui, Yumna Qureshi, Hamza Ben Yahia. Mechanical properties of graphene nanoplatelets reinforced epikote 828 under dynamic compression. Mechanics of Materials, 2021, 158, pp.103873. 10.1016/j.mechmat.2021.103873 . hal-03242640

HAL Id: hal-03242640

https://hal-ensta-bretagne.archives-ouvertes.fr/hal-03242640

Submitted on 3 Jun 2021

HAL is a multi-disciplinary open access archive for the deposit and dissemination of scientific research documents, whether they are published or not. The documents may come from teaching and research institutions in France or abroad, or from public or private research centers.
L'archive ouverte pluridisciplinaire HAL, est destinée au dépôt et à la diffusion de documents scientifiques de niveau recherche, publiés ou non, émanant des établissements d'enseignement et de recherche français ou étrangers, des laboratoires publics ou privés. 


\title{
Mechanical Proprieties of Graphene nanoplatelets Reinforced Epikote 828 Under Dynamic Compression
}

\author{
S. Khammassi (a, *), M. Tarfaoui (a, *), Y.Qureshi (a), H. Benyahia (a) \\ (a) ENSTA Bretagne, FRE CNRS 3744, IRDL, F-29200 Brest, France \\ *Corresponding author. E-mail address: sabrine.khammassi@ensta-bretagne.org \\ *Corresponding author. E-mail address: mostapha.tarfaoui@ensta-bretagne.org
}

\begin{abstract}
In this experimental investigation, the influence of graphene nanoplatelets (GNPs) on the dynamic behaviour of polymeric material such as diglycidyl ether of bisphenol A (DGEBA) epoxy is investigated using the Split Hopkinson Pressure Bar (SHPB). Nanocomposite samples with a different weight percentage of GNPs i.e. 0, 1, 2, 5 wt.\% were fabricated and tested under dynamic compression to understand the influence of nanofillers on the mechanical performance of the epoxy. The results established that changing the mass fraction of GNPs greatly influences the mechanical behaviour of the epoxy and confirmed that the optimal mass fraction of GNPs was 1 wt.\% because of the good dispersion and viscosity. While, a further increase in the percentage of GNPs resulted in degradation of the mechanical strength of the material because of the agglomeration of graphene sheets, porosity, and their poor interfacial bonding. Moreover, each mass fraction of nanocomposites was tested at three different impact pressures i.e. 1.5, 2, and 4 bar. The main objective is to quantify the effect of the strain rate on the mechanical behavior and on the resulting damage modes. This study further confirmed that the high percentage of GNPs increases the viscosity of the epoxy resulting in porosity and void in the structure which generates high-localised stresses into the matrix causing premature failure under dynamic loading.
\end{abstract}

Keyword: SHPB, Dynamic behavior, Compressive properties; Mechanical Behavior, Graphene, DGEBA, Nanocomposite 


\section{Introduction}

Polymeric materials with good performance are widely in demand for various applications for example transportation, construction materials, electronics, sporting goods, consumer products[1], [2]. However, the applications of pure polymeric materials are generally confined because of their low thermal and electrical conductivity and their less strength and high plasticity [3]. So, instead of individual, these polymers are often used in hybrid materials, for example, epoxies are one of the polymeric materials which are widely used as a matrix in a reinforced polymer (FRP) composite for high strength lightweight structures especially in aerospace and aircraft areas [4-5]. The mechanical behavior of the matrix plays a vital role in defining the strength and performance of the composite material [6]. Moreover, the interfacial bonding between reinforcement fibers and matrix is also important in designing composites with good damage tolerance and resistance [7]. Some researchers had enhanced the performance of the composite materials by incorporating micron-sized fillers such as rubber, elastomer, alumina, glass beads, and thermoplastics, also known as the traditional method to improve their performance [8-12]. However, these fillers presented some drawbacks including a decrease in failure strain, impact strength, and occasionally epoxy thermal stability and fracture toughness as Tarfaoui et al. found in their research work [13-17]. Then, the introduction of nanomaterials such as montmorillonite organoclay, nanosilica, carbon nanotubes, graphene, and nanofibers, etc. showed a better method to overcome these drawbacks [12], [16] [18-19]. The aim of incorporating these nanofillers was to improve the elastic modulus, strength, and toughness without sacrificing the strain to failure and thermal stability of the epoxy.

Recently, many researchers have been studying the influence of GNPs on the mechanical behavior of epoxy materials [20-21]. GNP, a plane monolayer of carbon atoms, strongly packed into a two-dimensional honeycomb lattice, was first discovered in 2004 [22]. GNPs have a breaking strength 200 times superior to steel, the ultimate bulk strength of $130 \mathrm{GPa}$, and fracture strength of $125 \mathrm{GPa}$ [23-25].

A variety of research work had has shown the influence of graphene in the polymer matrix [1920]. It has been stated that the mechanical properties of nanocomposites can be varied depending on many factors, like the essential matrices and fillers properties, the shape, size, aspect ratio and fillers volume fraction, the fillers and matrices interaction, the composite manufacture method. However, the excessive amount of GNPs fillers can modify the diffusion 
way resulting in voids and imperfections thus, degrading the performance of the material [28]. The influence of GNPs was explored by Tang et al. [29], Wang et al. [30] exanimated the size influence of the GNPs on tensile modulus and strength of a GNP/epoxy nanocomposite. The effect of the parameters of fabrication on the GNP/epoxy nanocomposite performance was studied by Pullicino et al. [26] and Poutrel et al. [31]. Later, King et al. [32] invented wellformed aerospace epoxy with two kinds of GNPs to estimate tensile properties. However, very little or no information is available regarding the dynamic behavior of polymer materials especially Epikote 828 in the literature. Moreover, it is vital to find the optimal wt.\% of the reinforcing material to ensure the prime performance of the material which was lacking from the previous research.

In this work, the influence of GNPs mass fraction and diffusion on the dynamic compressive behavior of epoxy was inspected and deliberated. A compressive Split Hopkinson Pressure Bar (SHPB) was used to investigate the dynamic mechanical behavior of graphene (GNP) reinforced Epikote 828 nanocomposites at high strain rates at different impact pressures. This work aims to examine the influence of different mass fractions of GNPs (1wt.\%, 2wt.\%, and $5 \mathrm{wt} . \%$ ) on the dynamic behavior of the epoxy polymer material at different impact pressures (1.5 bar, 2 bar, and 4 bar ).

\section{Materials}

The Epikote 828 pure resin consisting of diglycidyl ether of bisphenol A (DGEBA) was studied with poly(oxypropylene) diamine (Jeffamine D230) as a curing agent. Epikote resin 828 is classified as epoxy resin with a medium viscosity liquid formed from bisphenol A resin and epichlorhydrin. It comprises no diluent and offers perfect pigment wetting, resistance to filler settling, and excellent mechanical and chemical resistance properties in the cured state. However, as an unmodified pure bisphenol, Epikote 828 is likely to crystallize during storage mostly in cold conditions. The fabrication of nanocomposites first consisted of dispersing GNPs in the polymer matrix and then mixed using a planetary mixers method for a total of $60 \mathrm{sec}$ at $1400 \mathrm{rpm}$. Figure 1 shows a schematic diagram of the GNP/epoxy nanocomposite fabrication process. This planetary mixer type is a great model that hilts a big capacity of maximum $1 \mathrm{~L}$ and reaches deaeration at the submicron level. It presents an in-Cup Holder vacuum technology that could radically decrease the decompression time. Then the resulting mixtures were prepared by continuous impregnation of the GNPs using a 3-roll milling machine with three horizontally positioned rollers. Each roller rotates in an opposite direction from the adjacent roller with a 
tiny gap between them, creating a tremendous shear force that can finely disperse, mix, refine, or homogenize viscous materials. The mechanical characteristics of the material used are presented in Table 1. Sample plates of neat epoxy and nanocomposites with 1, 2, 5 wt.\% were prepared using the mold casting. A hand lay-up and compression hot press techniques were used to prepare final reinforced nanocomposite samples. Finally, the samples were pre-cured at $32^{\circ} \mathrm{C}$ for $16 \mathrm{~h}$, and then at $120^{\circ} \mathrm{C}$ for $1 \mathrm{~h}$. Each sample plate was $13 \mathrm{~mm}$ in thickness which was then machined to obtain $13 \times 13 \times 13 \mathrm{~mm}$ cube samples, Figure 2.

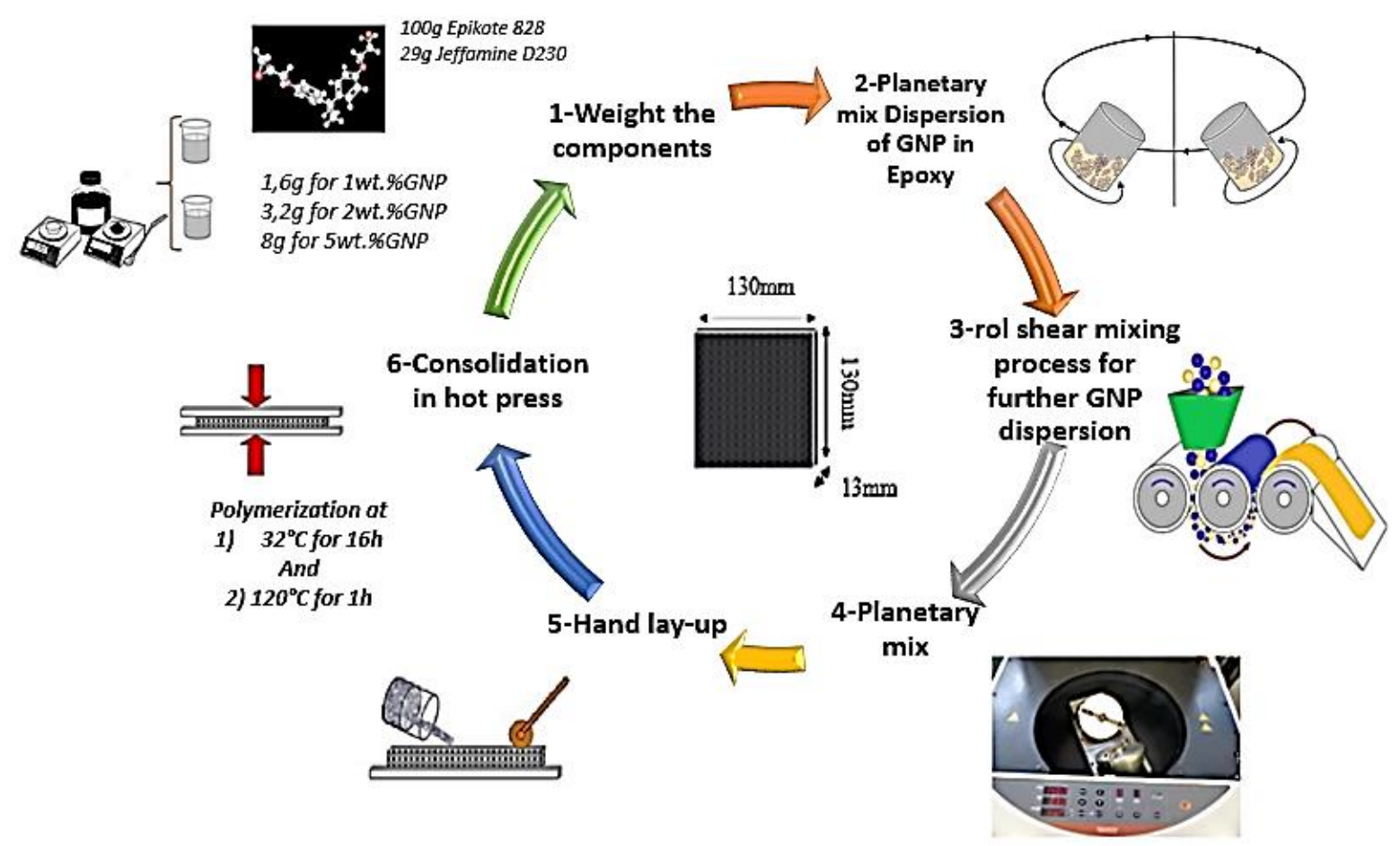

Figure 1: Schematic Diagram of Graphene /Epoxy Nanocomposite Fabrication

Table 1: Mechanical Characteristics of each material

\begin{tabular}{lcc}
\hline Materials & $\boldsymbol{E}(\boldsymbol{G P a})$ & $\boldsymbol{v}$ \\
\hline $\begin{array}{l}\text { Epoxy } \\
\text { matrix }\end{array}$ & $3.12 \pm 0.02$ & 0.35 \\
\hline GNPs & 1060 & 0.23 \\
\hline
\end{tabular}



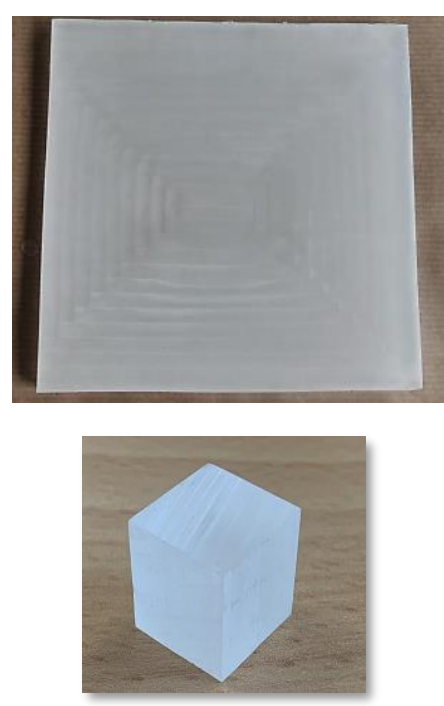

Neat Epoxy
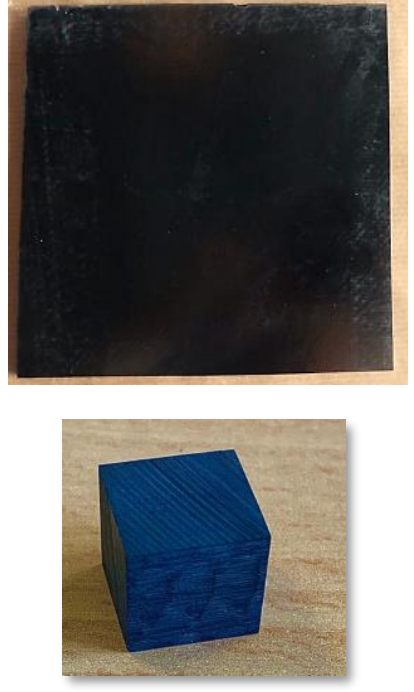

GNP/Epoxy Sample

Figure 2: Plates and specimens of epoxy and GNP/epoxy

\section{Experimental Process}

Split Hopkinson Pressure Bar, a standard test to assess the dynamic behavior of a material, was used to study the mechanical behavior of neat epoxy and nanocomposites with a different weight percentage $(1,2,5 \mathrm{wt} . \%)$ at high strain rates ranging between 200 and $10^{4} \mathrm{~s}^{-1}$ [3334][13], Figure 3. The SHPB apparatus consists of an incident, a transmitted, and sticker bars. The two bars and the striker are made from Inconel steel and have $20 \mathrm{~mm}$ in diameter. Both incident and transmitted bars have a length of $1.9850 \mathrm{~m}$ while the striker bar is $0.4 \mathrm{~m}$ in length which is used to generate an incident stress by impacting the incident bar. A high-speed camera FASTCAM SA-X2 TYPE 1080K-M4 was mounted to monitor the damage behavior, the resolution was set as $896 \times 496$ pixels at a frame rate of $33000 \mathrm{fps} / \mathrm{s}$. Specimens of reinforced epoxy nanocomposite are placed between the incident and transmitted bars without any attachment to prevent perturbations of measurements due to additional interfaces [35]. In a split second, the transmitted wave is reflected after the incident and these signals are recorded by the strain gauges attached to these bars [24] [36]-[38]. Furthermore, the striker velocity is adjusted by varying the pressure i.e. 1.5, 2, and 4 bar to achieve a range of incident load magnitudes and different compressive strain rates. 


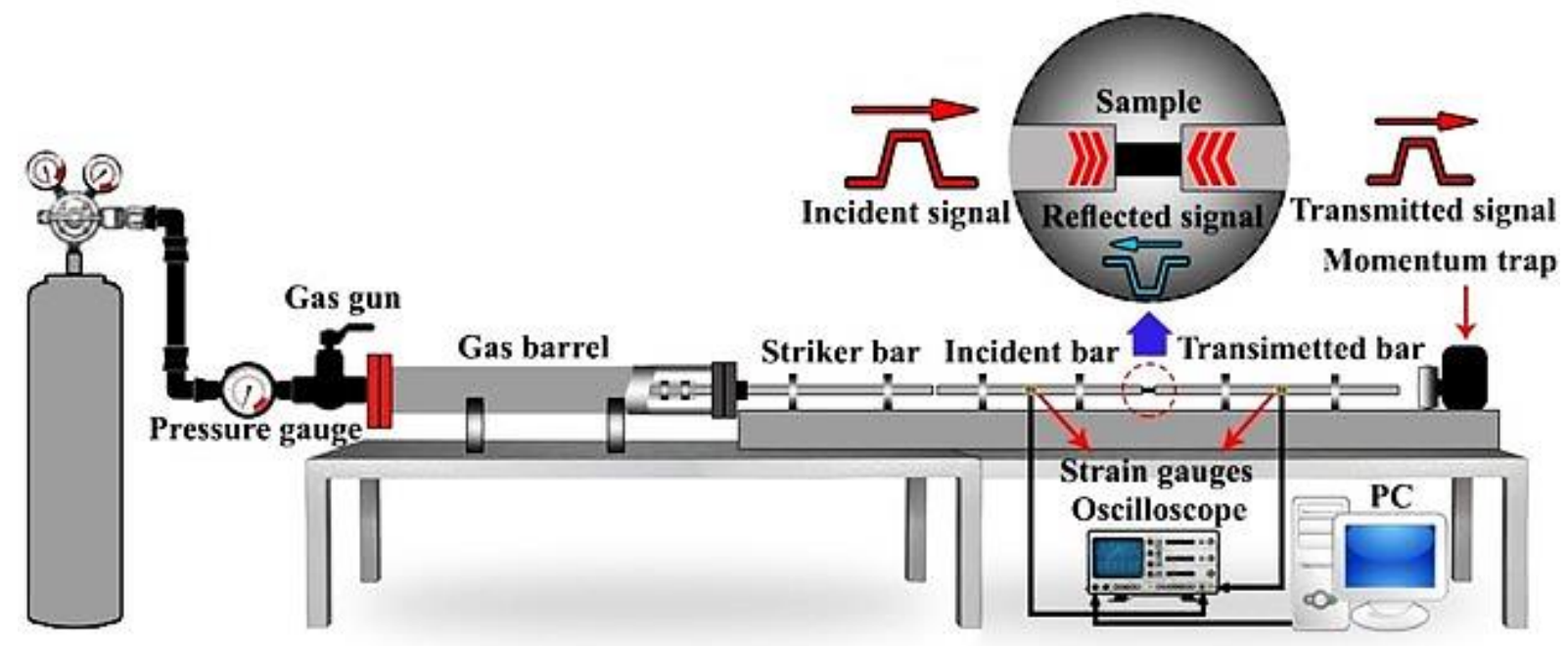

Figure 3: Split Hopkinson Pressure Bar

The SHPB signals were recorded and treated to determine the dynamic proprieties of the tested materials at different strain rate levels. When the striker impacted the incident bar axially with an initial velocity $\mathrm{V}_{0}$, an incident stress oscillation is produced. The incident stress wave $\left(\sigma_{i}\right)$ then strikes the interface between the sample and the bar and a reflected oscillation $\left(\sigma_{r}\right)$ is generated while a transmitted wave $\left(\sigma_{t}\right)$ is generated in the transmitted bar. Strain gauges are fixed on the incident and transmitted bars to record these oscillations [37].

The striker length is typically shorter than the incident bar and transmitted bar length with the same cross-sectional area. Under pressure impact, the elastic stress wave propagation speed C, incident pulse amplitude $\sigma_{i}$ and the duration of the formed incident stress pulse $\Delta \mathrm{t}$ could distinct as subsequent:

$$
\begin{aligned}
C & =\sqrt{\frac{E}{\rho}} \\
\sigma_{i} & =\frac{1}{2} \rho C V_{0} \\
\Delta t & =\frac{2 L}{C}
\end{aligned}
$$

E: Bar Young's modulus

$\rho$ : Bar mass density

$\mathrm{V}_{0}$ : Striker velocity

L: the length of the striker. 
Assuming stress equilibrium in the specimen yields, as it is shown in Figure 4 :

$$
\varepsilon_{t}(t)=\varepsilon_{i}(t)+\varepsilon_{r}(t)
$$

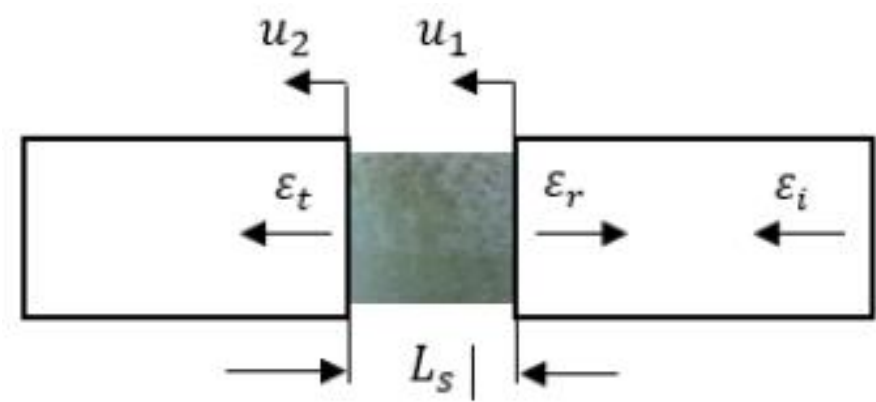

Figure 4: Expanded view of the incident bar/specimen/transmitted bar region.

The strain rate and engineering strain in the specimen are given respectively by equation (5) and (6):

$$
\begin{aligned}
& \dot{\varepsilon_{S}}(t)=-\frac{2 C \varepsilon_{r}(t)}{l} \\
& \varepsilon_{S}(t)=-\frac{2 C}{l} \int_{0}^{t} \varepsilon_{r}(t) d t
\end{aligned}
$$

Based on the 1-wave analysis, engineering stress in the specimen can be written as:

$$
\sigma_{s}(t)=\frac{A}{A_{s}} E \varepsilon_{t}(t)
$$

For the 3-wave analysis, the engineering stress is given by equation (8):

$$
\sigma_{s}=\frac{A E}{2 A_{S}}\left(\varepsilon_{i}(t)+\varepsilon_{r}(t)+\varepsilon_{t}(t)\right)
$$

The velocities on the incident and transmitted faces are given respectively by equation (9) and (10)

$$
V_{\text {inc }}(t)=C_{0}\left(\varepsilon_{i}(t)-\varepsilon_{r}(t)\right.
$$

Where:

A: Hopkinson bar cross-sectional area

$A_{s}:$ Sample cross-sectional area

$l$ : Sample initial length of the specimen 
$\varepsilon_{i}, \varepsilon_{r}$ and $\varepsilon_{t}$ : the incident reflected and transmitted strain values into the bars

$C_{0}$ :wave propagation speed.

\section{Results and Discussion}

\subsection{Test reproducibility}

Figure 5 shows that during the dynamic compression test, the signal indicates that both the incident wave and the transmitted wave are compression waves, and the reflected wave is tensile. Neat Epikote sample at 1.5 bar, 2 bar and 4 bar pressures demonstrated that the incident, transmitted and reflected waves behavior changed drastically with the increase in the striker bar velocity. Besides, the strain deformation behavior of the sample at each pressure presented that the sample reached its maximum value upon strike then gradually reduced. Afterward, the negative drop in the behavior of the sample tested at 1.5 bar presented the spring back behavior or elastic recovery of the sample. While a small but significant appearance of a second peak in the behavior of the samples tested at 2 and 4 bar, demonstrated the appearance of microcracks begins within the sample. Generally the larger the second peak, the higher the amount of permanent damage that can be present in the sample. For example, the start appearance of the second peak in the test executed at 4 bar confirmed the initiate presence of microdamage in the neat epoxy samples. However, at the same time, the sample tested at 1.5 bar indicated an elastic response or recoverable behavior during dynamic compression [23].

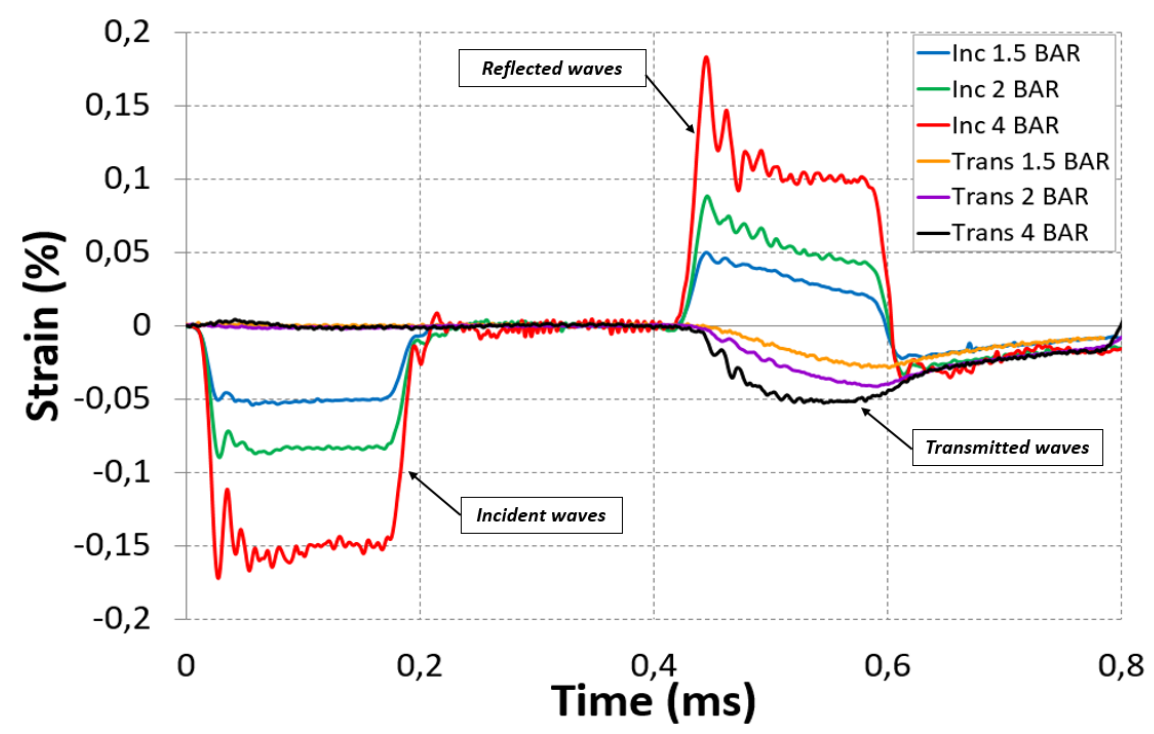

Figure 5: Neat Epikote Strain vs Time Curve for different impact pressure 
Before starting an experimental study for a dynamic case, it is indispensable to ensure that the test can be replicated. With this goal in mind, for each mass fraction, at least three tests need to be performed under the same impact pressure to analyze the test reproducibility. As shown in Figure 6, notice that the tests are repeatable, and each test checks a fact. The graph shows the strain rate vs time curve.

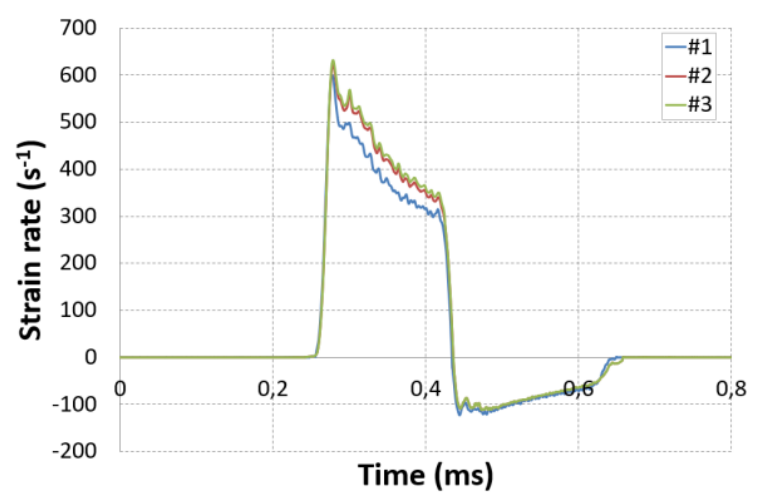

(a) Neat Epoxy

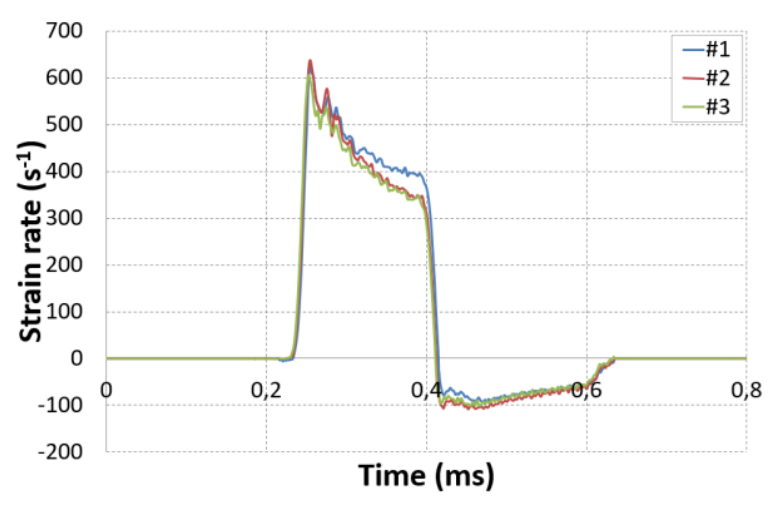

(c) $2 w t . \%$ GNP

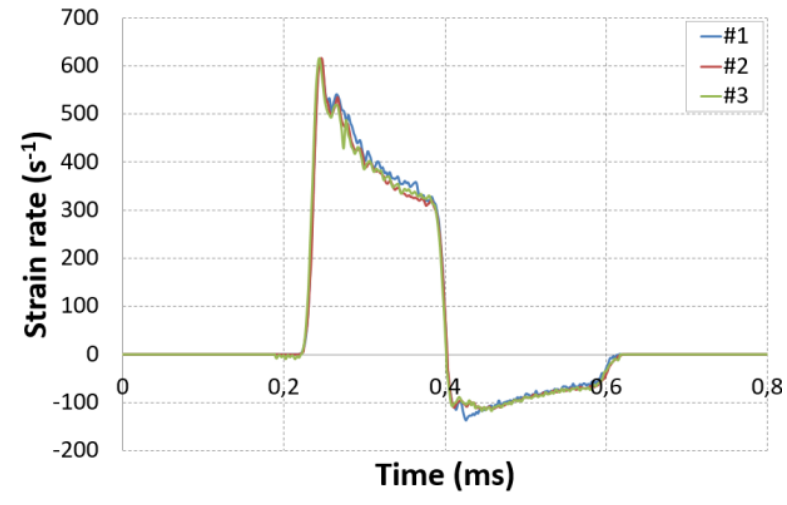

(b) $1 w t . \%$ GNP

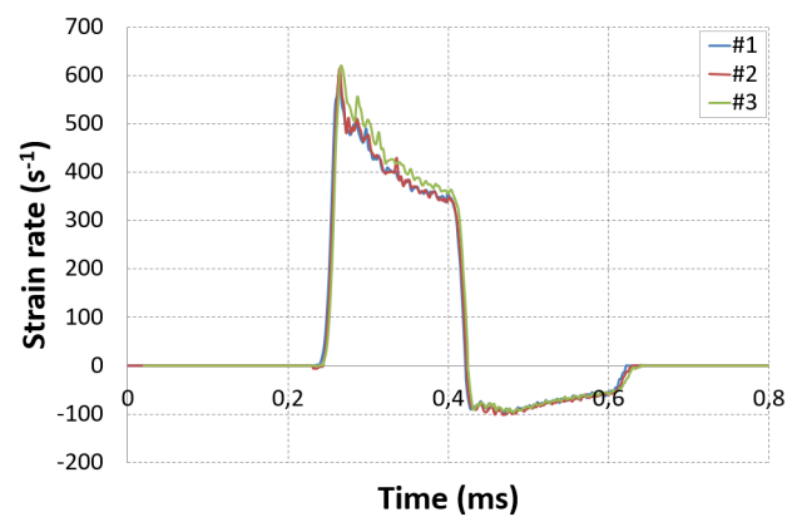

(d) $5 w t . \%$ GNP

Figure 6: Test reproducibility of the nanocomposites with neat epoxy and wt.\% GNPs mass fractions, $\mathrm{P}=2$ bar

\subsection{Influence of nanofillers on the dynamic behavior of GNPs/epoxy nanocomposites}

Nanocomposite specimens with, 1wt.\%, 2wt.\%and 5wt.\% of GNPs were inspected under dynamic compression test at three impact pressures i.e. 1.5 bar, 2 bar and 4 bar similar to neat epoxy samples. Figure 7 showed that GNPs integration into Epikote 828 influenced its dynamic characteristics. The velocity vs. time behavior showed that an increase in impact pressure increased their peak velocities. At 1.5 and 2 bar, no significant improvement in the velocities 
was overserved with the change in the percentage of GNPs and no second peak was recorded. While the velocity behavior increases rapidly with the increase in wt $\%$ of GNPs at 4 bar [39]. At 4 bars, a small but visible second peak was observed in the results which confirms the presence of damage within the samples and the apparent beginning of the second peak became more prominent with $2 \mathrm{wt} . \%$ and $5 \mathrm{wt} . \%$ of GNPs which is consistent with the following works [13], [24-25], [28-32], [40]. Tarfaoui studies proved that the location of the macroscopic damage can be determined by the presence of a second peak on the $\dot{\varepsilon}=f(t)$ curve. The formation of this peak corresponds to a decrease in stress. Tarfaoui et al. [41-44] discussed in a large number of their studies that the existence of the second peak in the reflected wave represents the existence of macroscopic damage in composite materials. The first observation that can be made is that the material shows higher strength. Damage only occurs under high impact pressure which is reasonable when there is a second peak in the signal and becomes more obvious as the impact pressure increases, which reflects the accumulation of failure modes in the sample. On the contrary, for low impact pressure, there is only residual "plastic" deformation in the matrix

One can also notice that the nature of the damage is strongly influenced by the mass fraction of graphene added to the DGEBA matrix and the random way the graphene flakes take to change the behavior of the reinforced epoxy nanocomposite material. These results presented in Figure 7 show not a very huge appearance of the second peak, but this level proves already the micro crack creation. It shows important residual plastic deformation due to cracks in the matrix, which may be worst if the impact pressure exceeds 4 bar, and involves a catastrophic failure of reinforced epoxy nanocomposites. As the strain rate increases, more failure mechanisms are involved; from matrix cracking to final fracture. 


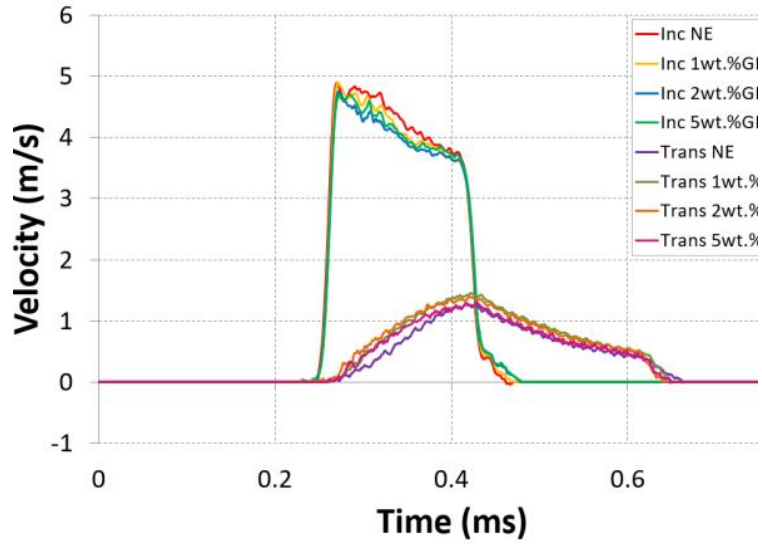

(a) $1.5 \mathrm{bar}$

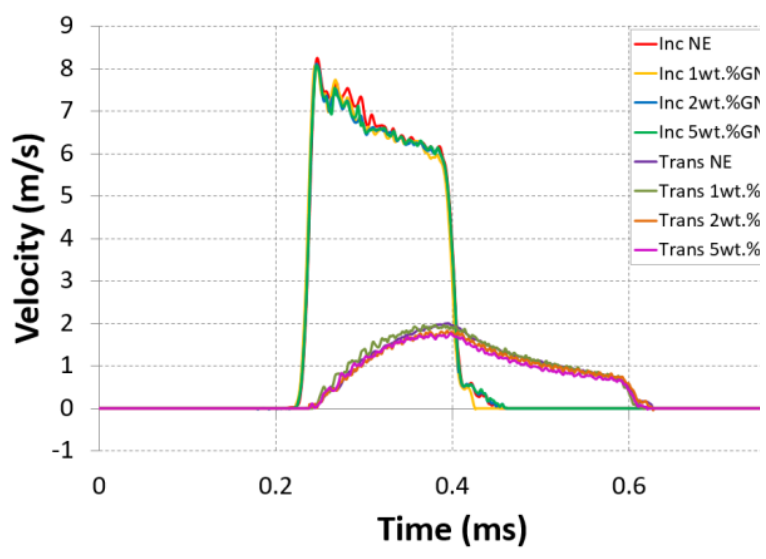

(b) $2 b a r$

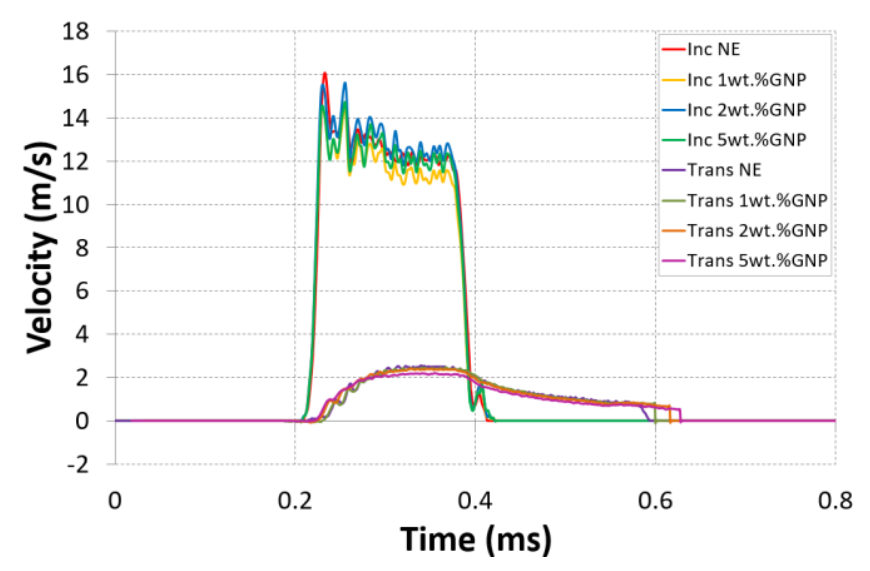

(c) 4 bar

Figure 7: Incident and transmitted velocities for GNPs/Epoxy nanocomposites under different impact pressures

\subsection{Effect of GNPs incorporation on the strain rate response}

Figure 8 hand over the GNPs reinforced Epikote 828 nanocomposite specimens tested at 1.5 bar, where an elastic-plastic deformation through all percentages overstrains deformation rate. The strain rate behavior showed a negative drop in the behavior of all these specimens, which verified the spring-back effect. Figure $8 \mathrm{a}$ shows, at $1.5 \mathrm{bar}$, the strain rate of nanocomposite samples decreased with the introduction of GNPs however, each sample showed elastic-plastic deformation with enhanced elastic behavior because of higher strength and stiffness in comparison to neat epoxy samples. Figure $8 \mathrm{~b}$ reveals at $2 \mathrm{bar}$, the sample showed similar performance with higher peak values with a small difference in the behavior with the change in the wt.\% of GNPs. Figure 8c shows the strain rate vs time at 4 bar, where the neat epoxy resin 
and GNPs-reinforced Epikote 828 nanocomposite sample shows a onset second peak, which is the main feature of these curves. The second peak characterizes the beginning of mac/microscopic damage which we will introduce in detail in Section 4.4.

2wt.\% and 5wt.\% GNPs showed a higher second peak compared to $1 \mathrm{wt} . \%$ GNPs which explain that higher mass fraction increased the viscosity of the matrix and make a non-uniformed distribution. Damage and energy-absorbing mechanisms of neat resins under high strain rate loading consisted of the formation of cracks. The increase in damage and energy-absorbing mechanisms with the dispersion of nanoparticles into resins was because of the nanoparticle debonding and the appearance of the phenomenon of agglomeration [25].

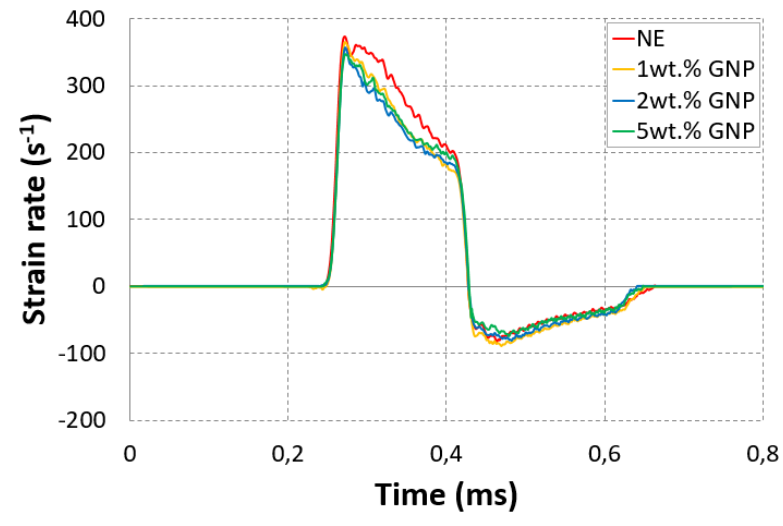

(a) 1.5 bars

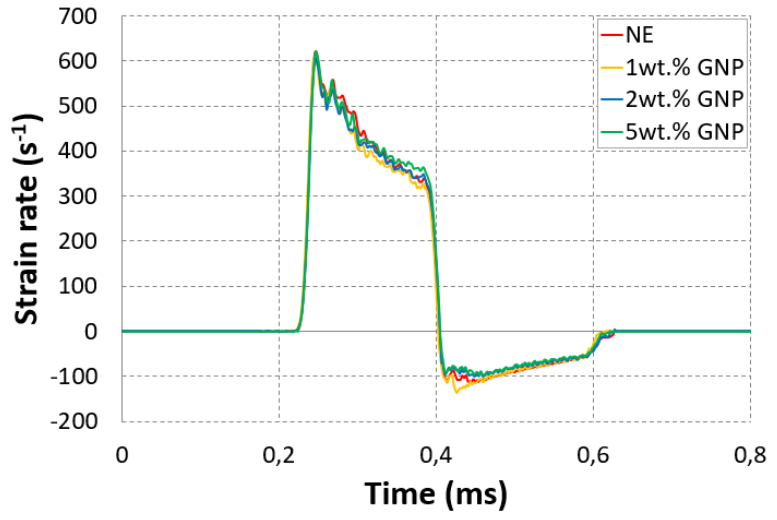

(b) 2 bars

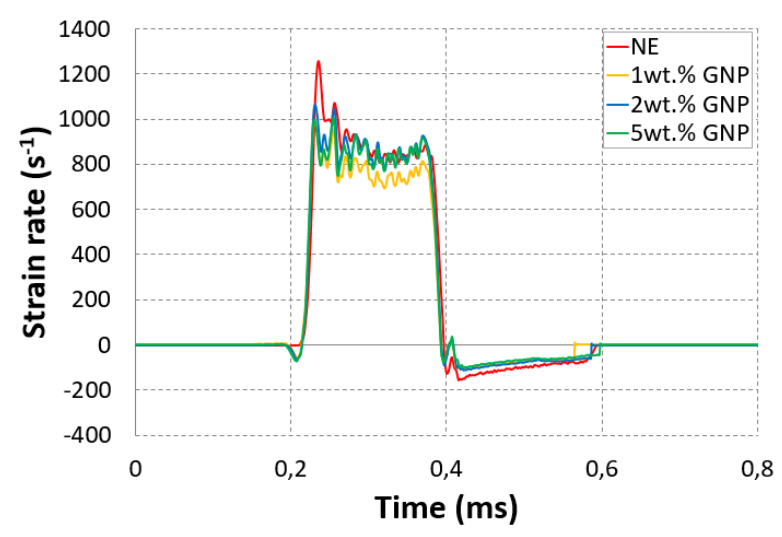

(c) 4 bars

Figure 8: Strain rate vs. time for a different mass fraction

Generally, the dynamic compressive strength increases with the increase in strain rate because, at lower strain rates, the damage propagates slowly using most of the applied energy. However, 
the macro damage existence at higher strain rates, because there is not sufficient time for the epoxy polymer chains to attend the instant strain thus, result in reduced polymer mobility[42]. The eventual strength of all samples indicates a decreasing tendency in the strain rate, while the strain energy at fracture is nearly stable. The resin viscoelastic nature also seems to be accountable for the dynamic compressive strength development [34]. Further, a high mass fraction of reinforcement GNPs affects the viscosity of the structure and generates a weak interaction bonding with the matrix that can result in degradation of the mechanical behavior of the epoxy [45].

\subsection{Effect of GNPs on the stress-strain behavior of the Epikote 828 nanocomposite}

Samples tested at 1.5 bar showed that the introduction of GNPs influences the stress-strain behavior of the epoxy greatly as it is demonstrated in Figure 9a. Moreover, the results showed that with an increase in the wt.\% of GNPs the stiffness and strength of the material was increased and ductility was reduced where the permante plastic deformation of GNP reinforced epoxy nanocomposite decrease compared with neat epoxy. However, samples with 5wt.\% GNPs showed degradation of mechanical performance in comparison with other weight percentages. This behavior is observed because of the decrease in molecular epoxy chains mobility which consequence of stiffer chains [46]. Furthermore, the samples tested at 2 bar impact pressure showed that $1 \mathrm{wt} \%$. of GNPs improved the behavior of epoxy material by increasing the stiffness and resilience of the material. However, Figure $9 \mathrm{~b}$ presente that samples with $2 \mathrm{wt} . \%$ and $5 \mathrm{wt} . \%$ GNPs showed a decrease in strength and an increase in permanente plastic deformation of the material. This degradation of properties could be because of the high mass fraction of GNPs sheets that affected the viscosity of the matrix epoxy and generated a nonuniform diffusion [47]. Samples tested at 4 bar showed a clear difference amongst the stressstrain behavior of the neat epoxy and nanocomposites as it is presented in Figure 8c. It showed a ductile behavior where there is a transition from elastic to plastic behavior with a visible rise in the material yield strength and dynamic Young's modulus as demonstrated in Figure 11. Additionally, an obvious increase in the plasticity with increasing mass fraction of GNPs was observed in comparison to neat epoxy. Samples with 5wt.\% GNPs presented important permanent damage in the sample, which was gradually reduced as the wt.\% of GNPs was reduced i.e. $2 \mathrm{wt} . \%$ than $1 \mathrm{wt} . \%$. It was observed that the dynamic fracture toughness changed with the mass fraction of GNPs sheet where the plastic deformation evaluates with the impact pressure. Figure 10 synthese the behavior evolution where it present maximum Stress vs 
GNP mass fraction under different impact pressure. Higher mass fractions of GNPs affected the structure viscosity and resulted in the void formation which was confirmed by the SEM morphology [46] in Figure 11. Figure 11 shows that under 1wt\% GNPs, the structure of nanocomposites has a clear morphology without interfering elements, but at $2 \mathrm{wt} \%$ GNPs, the appearance of huge porosity is very clear, which can degrade the properties of nanocomposites. On the other hand, under 5wt\% GNPs, because the important added graphene mass fraction touches the structural viscosity, the morphology of the nanocomposite is completely changed and becomes rough, sharpened and cracked.

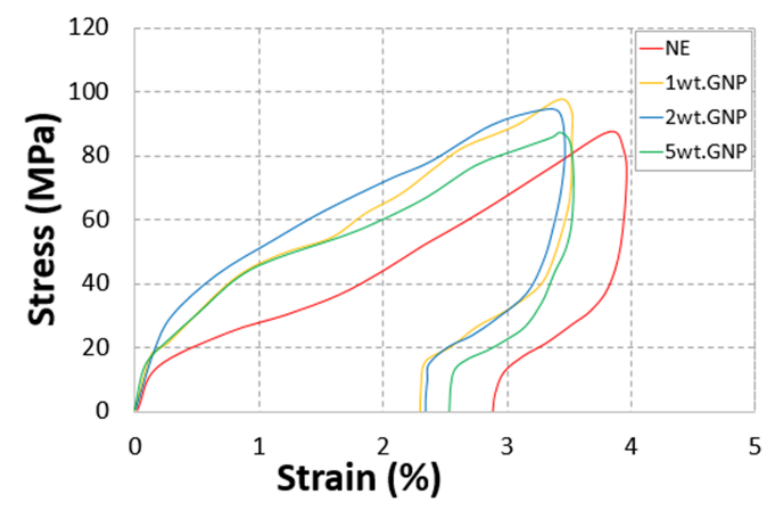

(a) 1.5 bars

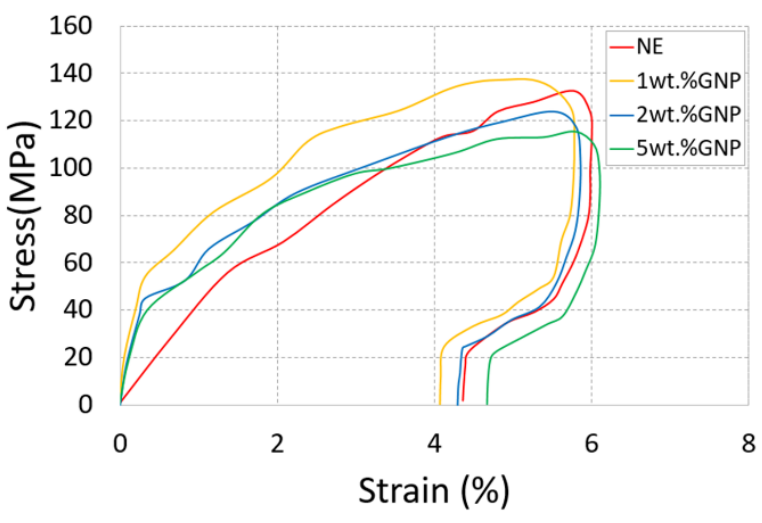

(b) 2 bars

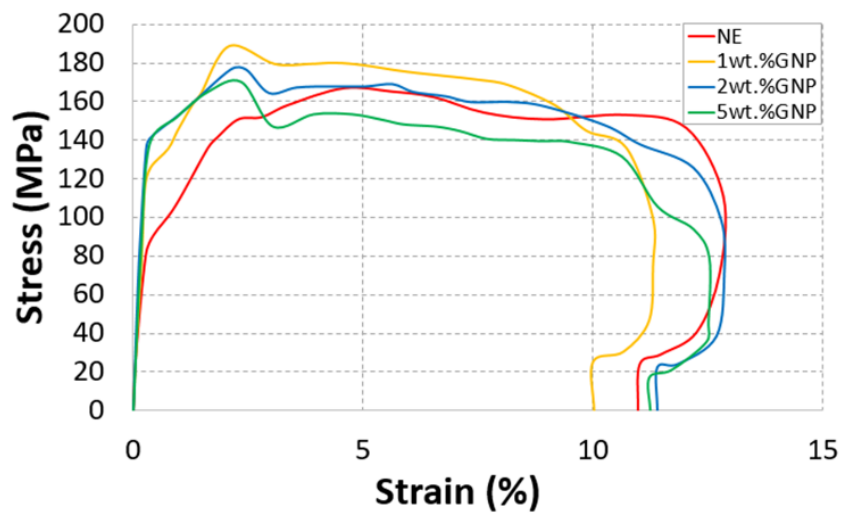

(c) 4 bars

Figure 9: Stress vs. strain at different impact pressures 


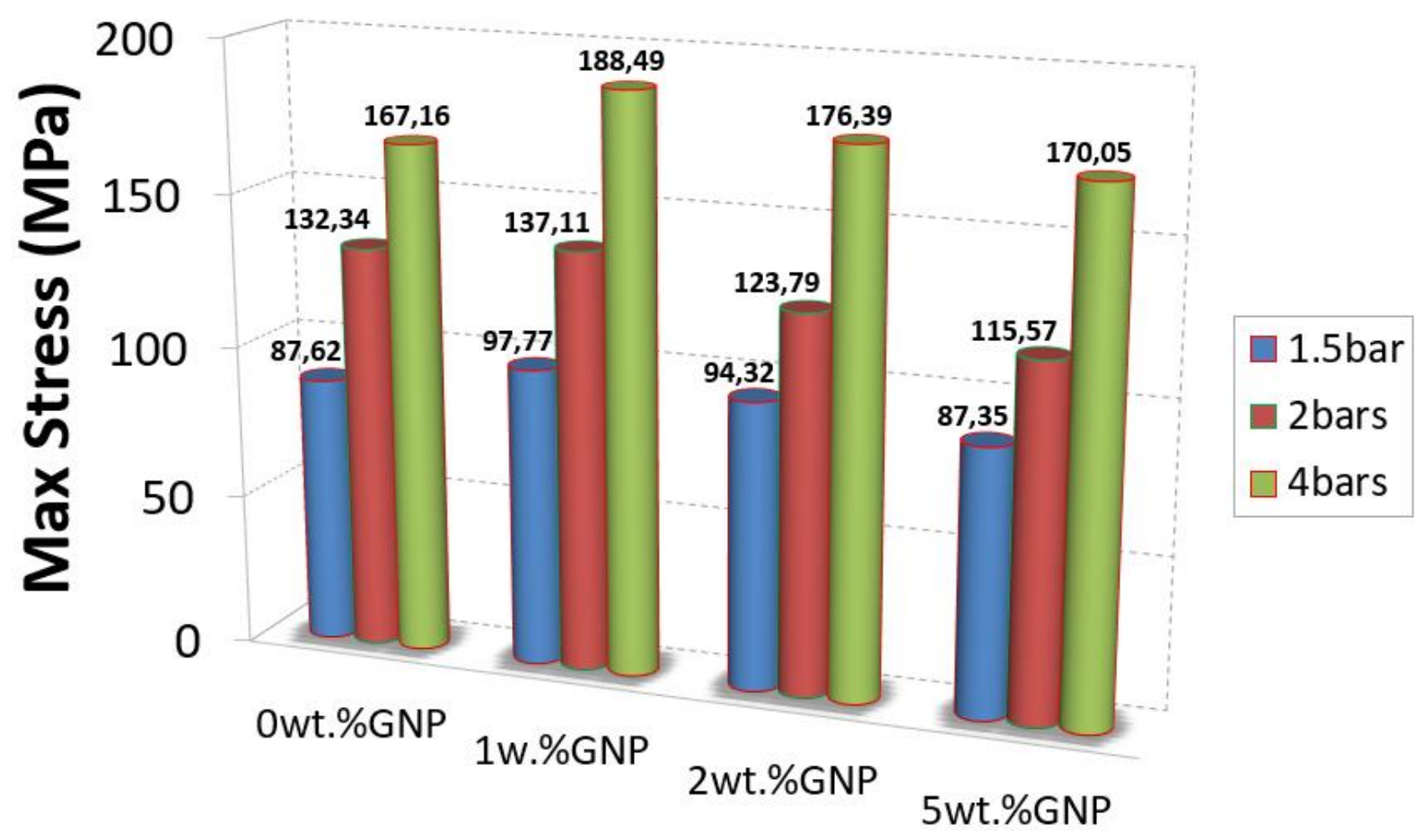

Figure 10 :Maximum Stress vs GNP mass fraction with different impact pressures GNPs particles with their good stiffness were integrated into the neat epoxy and were located in the spaces existing among the polymer chains, which reduce the flexibility of the chain. This in return decreased the reinforcing efficiency of GNPs at higher impact pressures, since it is expected that the polymer chains have already been stiffened and the matrix seemed like a new and relatively stiffer epoxy. This concludes that the positive reinforcing characteristic of nanoparticles reduced as the stiffness of the matrix increased. 


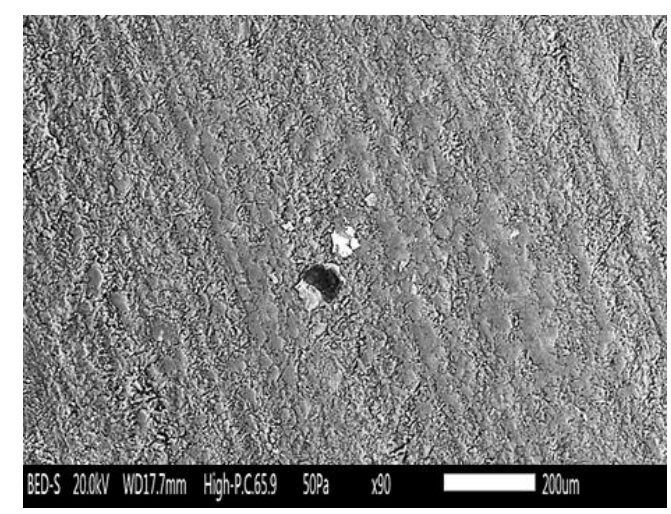

(a) $1 \%$ wt. GNP

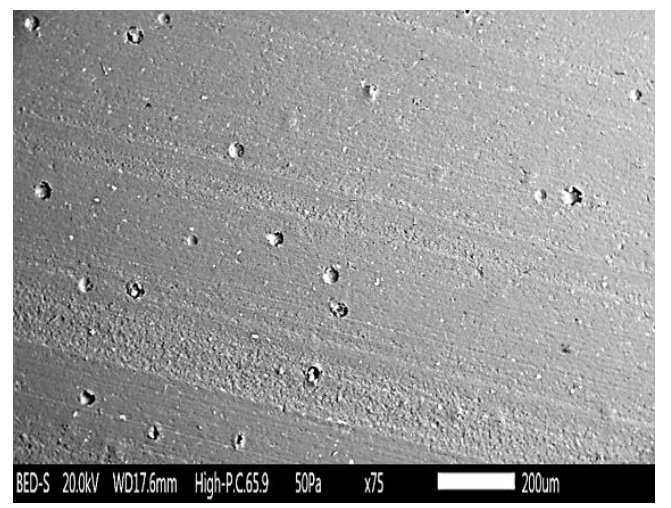

(b) $2 \%$ wt. GNP

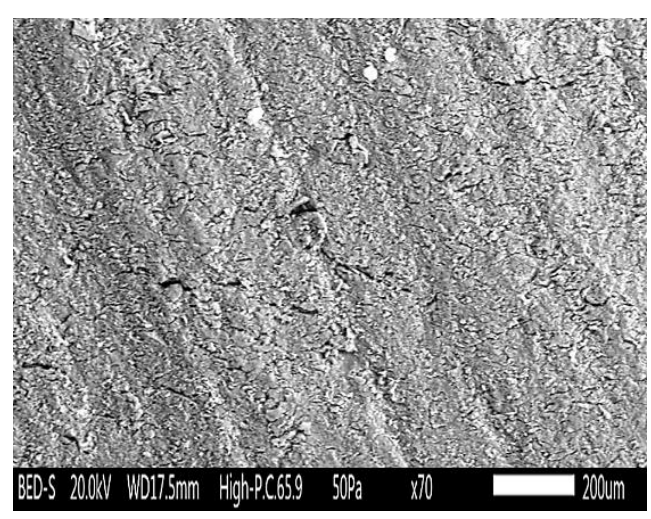

(c) $5 \%$ wt. GNP

Figure 11: SEM micrographs of the degradation of nanocomposite structure with $1 \mathrm{wt} . \%$, 1wt.\%, 2wt.\% GNP at 4 bar

In addition, the maximum strain rate and maximum strength are proved by the phenomenological law, which can explain the influence of impact pressure, thus providing a framework for modeling the dynamic behavior of nanocomposites under impact for optimization design purposes as it is presented in Figure 12(a). Use the error sensitivity curve to calculate the average of all results under each impact pressure. The change of impact rate 
proves the change of strain rate, and the accuracy of curve fitting exceeds $99 \%$. The results in Figure 12(a) show that by increasing the impact pressure of the graphene-reinforced epoxy nanocomposite, the strain rate becomes more prominent. However, the introduction of GNP reduced the evolution of strain rate by up to $1 \%$, and the curve fitting accuracy was $99 \%$. Similarly, Figure 12 (b) showing the evolution of the maximum stress is also strongly dependent on the impact pressure, and the curve fit precision is $99 \%$. The results in Figure 12(b) show that the maximum strength increases with the increase of impact pressure, and the maximum increase in strength of samples with $1 \%$ GNP increases with the increase of dynamic impact pressure. Therefore, the introduction of GNP up to $1 \mathrm{wt} \%$ not only improves the maximum strength of the sample but also improves the dependence of these dynamic characteristics under dynamic compression to achieve the purpose of design optimization. 


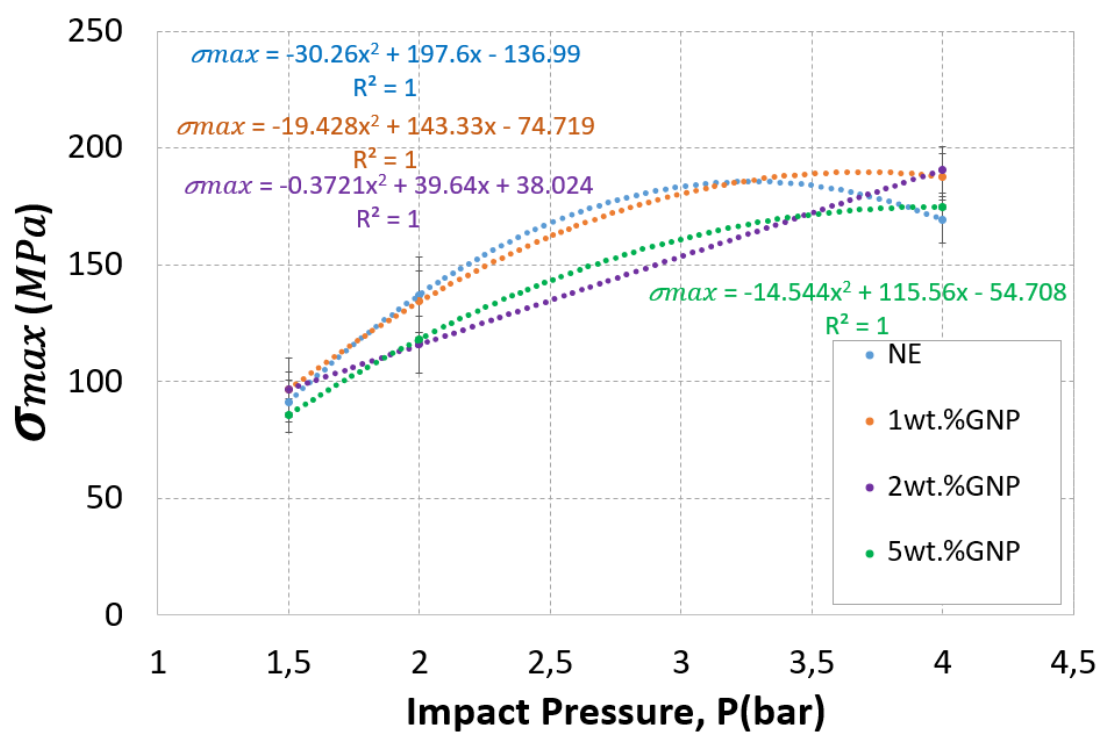

(a)

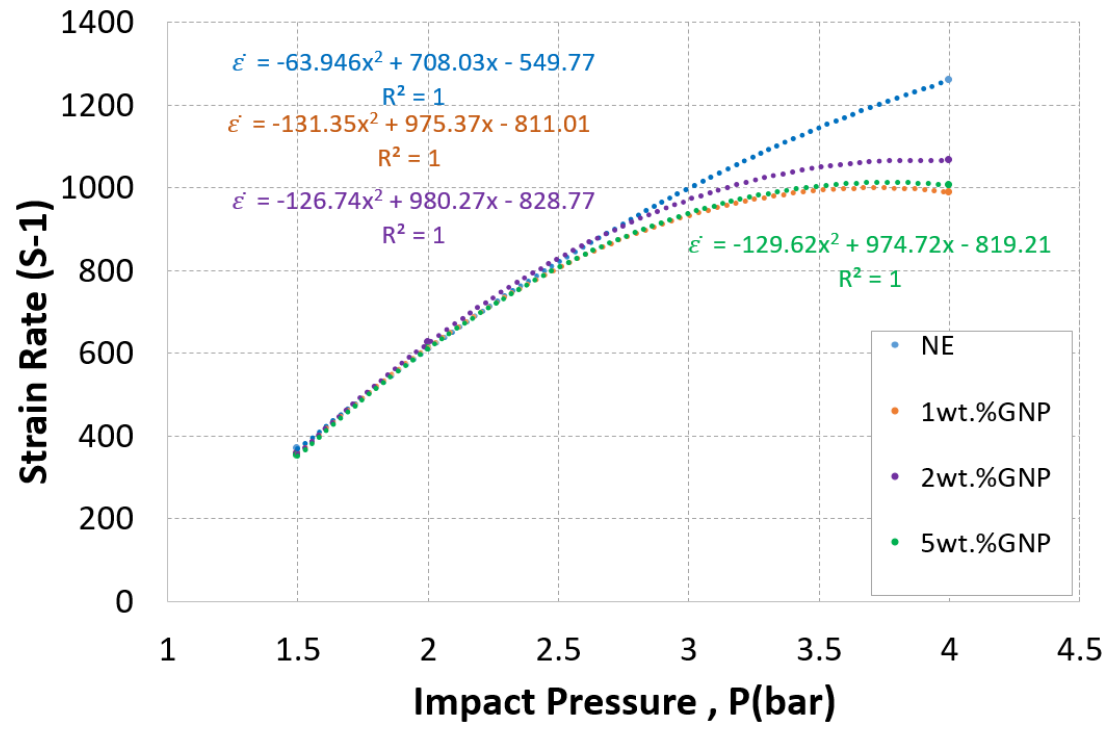

(b)

Figure 12: Evolution of dynamic parameters of GNPs/epoxy nanocomposites

\subsection{Dynamic behavior and damage history}

With the different strain rates, the damage progress in the GNPs reinforced Epikote 828 nanocomposite samples at the dynamic compression test was exanimated. Accordingly, the development of the association of the stress-time curves and strain rate-time curve under the three different impact pressure was shown in Figure 13. Figure 14 illustrates the evolution of the dynamic Young modulus of GNPs reinforced nanocomposite under different strain rates. The correlation amongst these curves tinted the existence of three zones for the non-damaging case and four zones for the damaging case which described as subsequently: 
(a) The non-damaging case for 0 wt.\%, 1wt.\% GNPs at 1.5 and 2 bars (Figure 13a13b):

Zone A was considered by a fast strain rate increase that can be associated with the specimen self-installation between the bars, where it is clear the young modulus increases with the incorporation of GNPs accompanied simultaneously with the slight rise of the strain rate.

Zone B presented that good contact among the bars was realized. The material strength generates a gradual decrease with strain rate and the stress keeps rising continuously to a maximum value under compression loading. This correlation of results confirms that GNPs incorporation indicates an improvement in the Epikote 828 performance with 1wt.\% GNPs.

Zone C: following the achievement of maximum value, the stress, strain rate, commenced reducing. In this region, the strain changed sign while the stress attended to achieve a zero value. This behavior is linked to the spring back of the material. This zone-reinforced structure with 1 wt.\% tried to reduce the plastic deformation more compared to neat Epikote and nanocomposite.

\section{(b) The damaging case for 0wt.\%, 1wt.\% CNPs at 4 bar (Figure 13c):}

Zone A some progress to the non-damage case

Zone B some progress to the non-damage case

Zone $\mathbf{C}$ was identified by the stabilized maximum values of the stress and the strain rate under dynamic compression. This obvious aspect can be credited to the presence of microscopic damage in polyester (matrix plasticity, matrix cracks ... etc.) under dynamic compression loading. These structure responses approve that incorporation GNPs reinforcement Epikote nanocomposite can fail at high strain rate but $1 \mathrm{wt} . \%$ GNP reinforced nanocomposite still even with a case much better than neat Epikote and delay the failed structure moment.

Zone D was identified by rapid reduction of each signal. One might clarify this behavior by the intensification of microscopic damage into the polymeric sample concerned with the existence of macroscopic failure modes. After the full failure, it could realize that all the signals tried to achieve zero values. Herein it is clear that reinforced structure with $1 \mathrm{wt} . \%$ achieved zero the first one where it tried to reduce as much as it can the plastic deformation. 


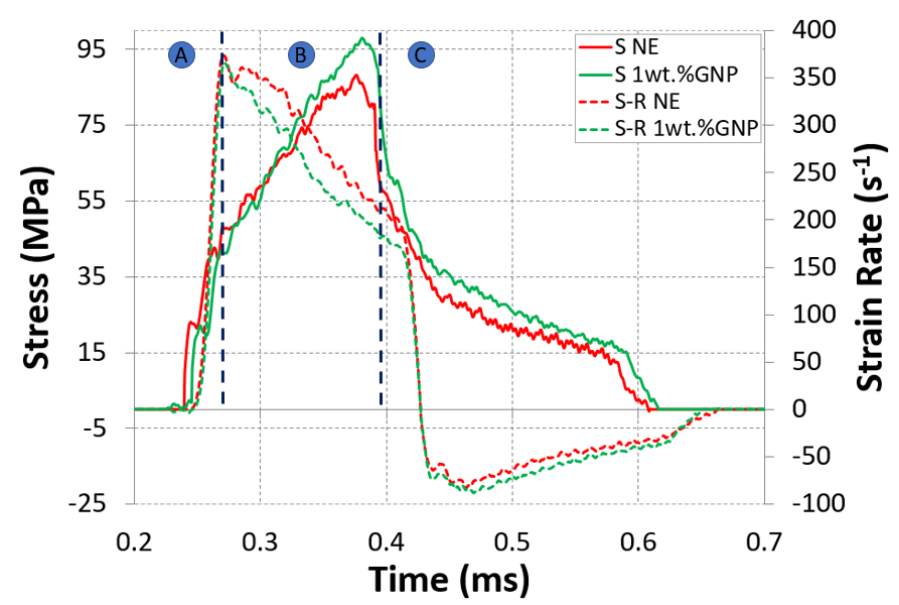

(a) $1.5 \mathrm{bar}$

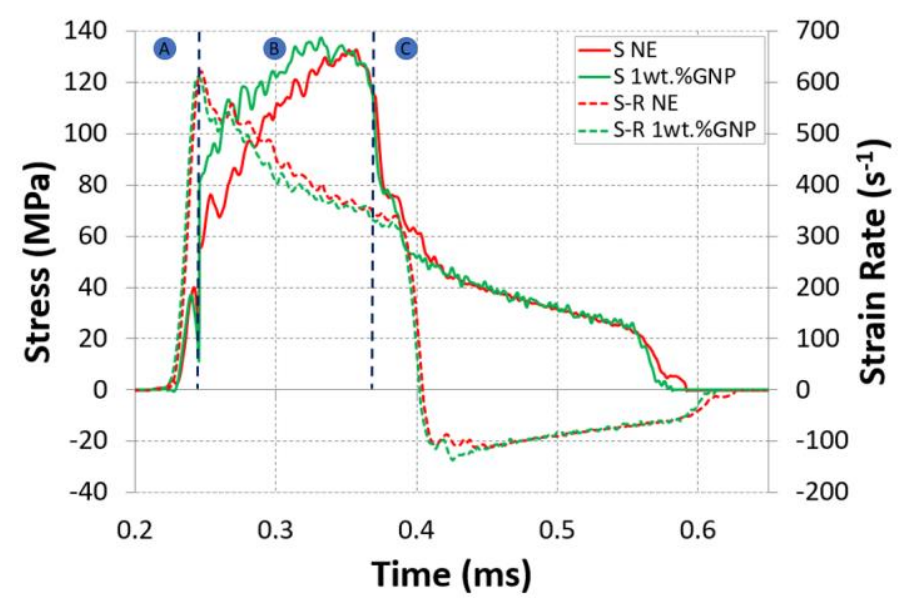

(b) 2 bar

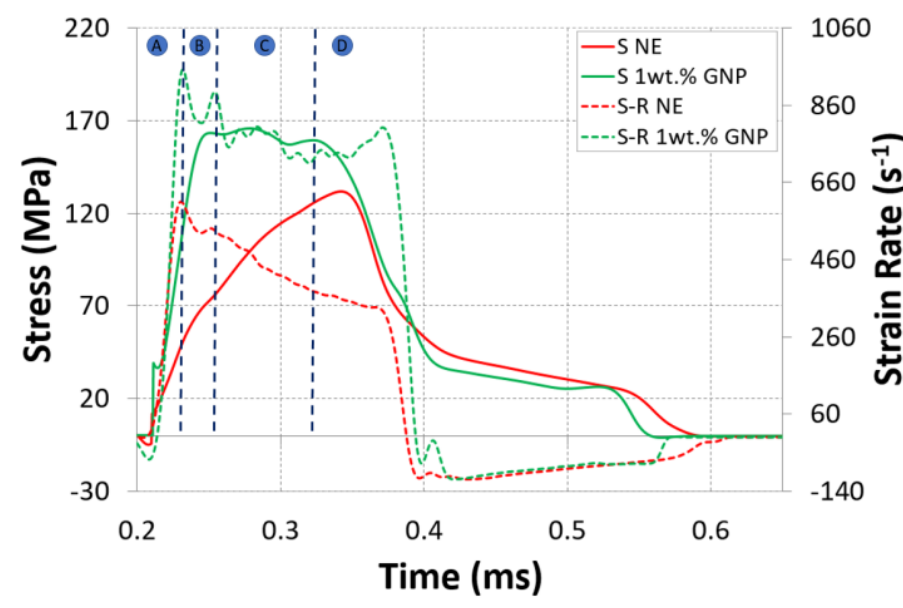

(c) 4 bar

Figure 13: Stress-Strain rate vs Time 


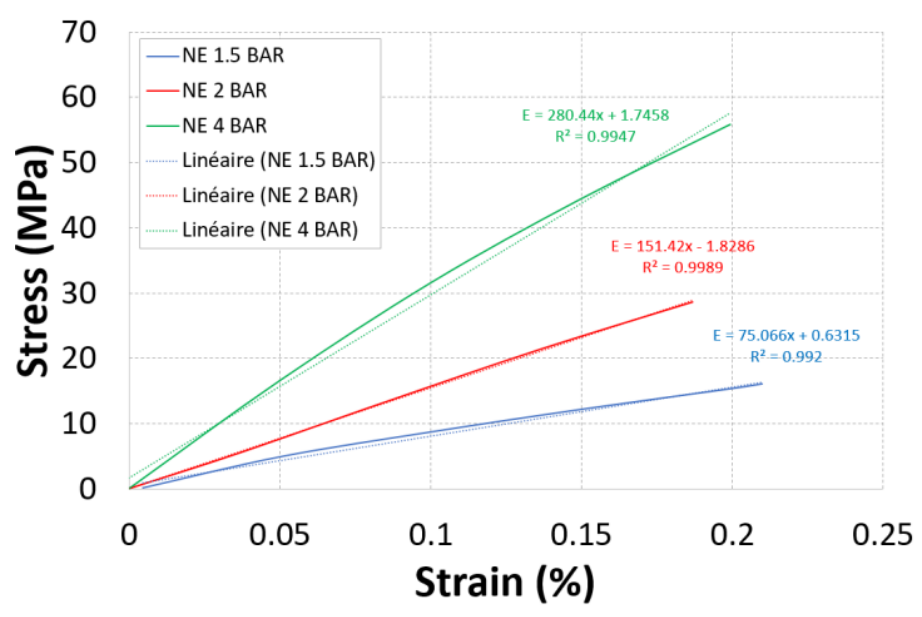

(a) Neat epoxy

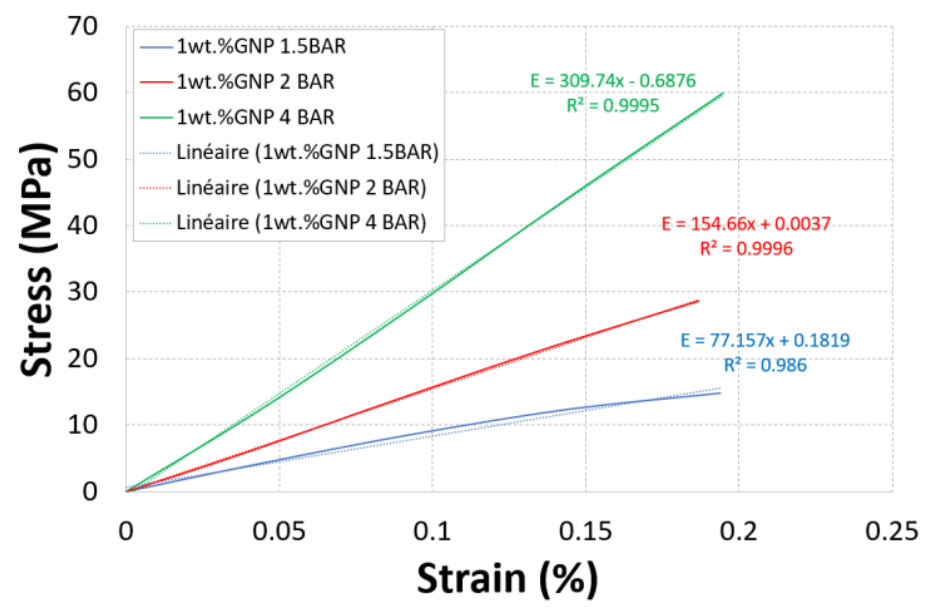

(b) GNPs/epoxy nanocomposite, 1wt.\%

Figure 14: Dynamic Young modulus evolution for GNPs/epoxy nanocomposites.

To understand the deformation process of the GNPs reinforced Epikote nanocomposite under dynamic loading, a high-speed camera (FASTCAM SA-X2 TYPE 1080K-M4, the resolution was set as $896 \times 496$ pixels at a frame rate of $33000 \mathrm{fps} / \mathrm{s}$ ) was used to monitor the damage behavior. Figure 15 shows an example of the compression deformation process of samples with 1 wt.\%., 2 wt.\%., 4 wt.\%, and neat epoxy at high-pressure 4 bar. These observations of the highspeed camera confirmed the behavior observed in the stress-strain results. Green and red lines are superposed on the camera photo to show the dimension difference between the sample before compression ( $\mathrm{t}=0 \mathrm{~ms}$ ) and other induction periods (when the green line presents the sample initial dimension ). 
However, no macro-destruction of the nanocomposite samples was observed but the appearance of the second peak in the curve of strain rate versus time suggested the presence of damage. Micro- and nano-scale damage such as plastic deformation, micro-buckling, kink bands, and cracks could occur. Incorporation of GNPs not only increases the material strength but also shows a vital role in retarding the crack propagation phenomenon if it will happen, thereby improving the material resistance to the final fracture. 


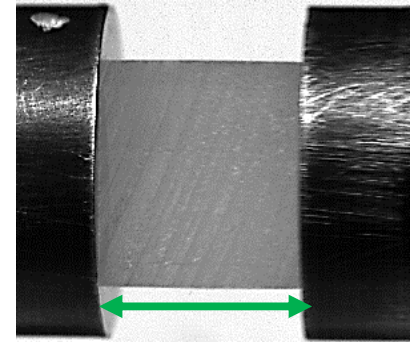

Zone $\mathrm{A}=0 \mathrm{~ms}$

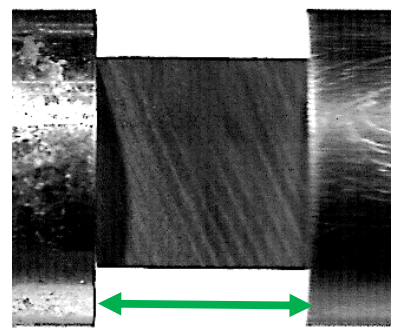

Zone $\mathrm{A}=0 \mathrm{~ms}$

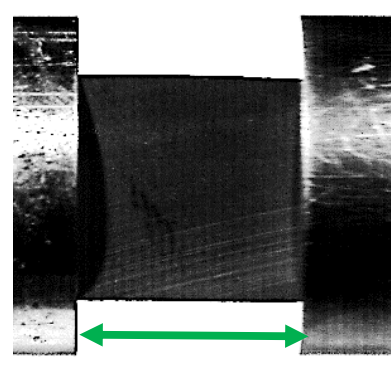

Zone $\mathrm{A}=0 \mathrm{~ms}$

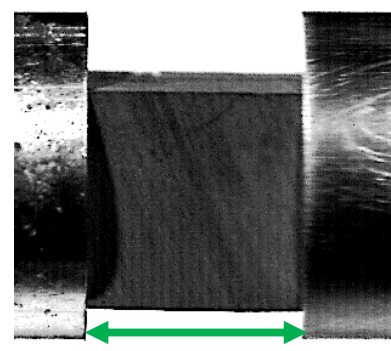

Zone $\mathrm{A}=0 \mathrm{~ms}$

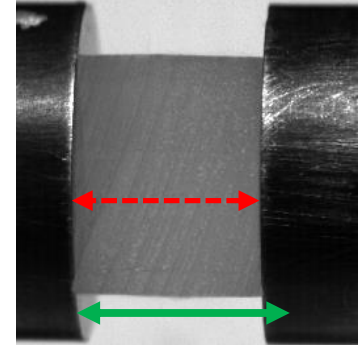

Zone $\mathrm{B}=0.267 \mathrm{~ms}$

(a) NE

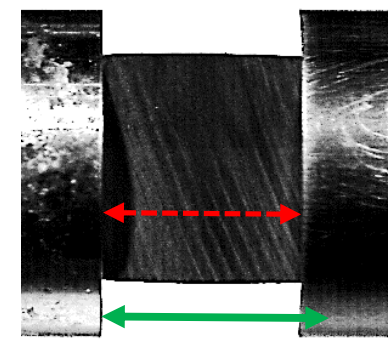

Zone $B=0.262 \mathrm{~ms}$

(b) $1 w t . \% G N P$

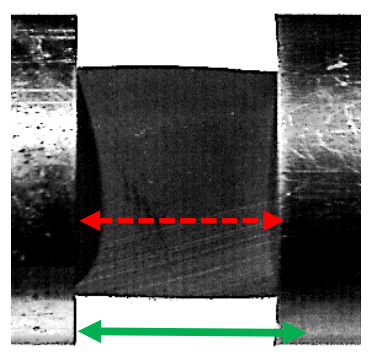

Zone $\mathrm{B}=0.267 \mathrm{~ms}$

(c) $2 w t . \% G N P$

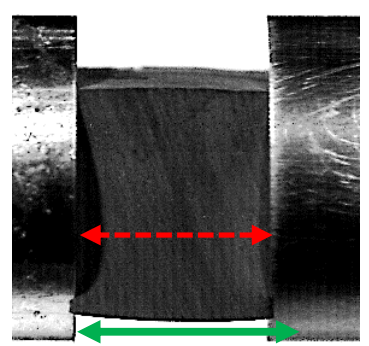

Zone $\mathrm{B}=0.255$

(d) $5 w t . \% G N P$

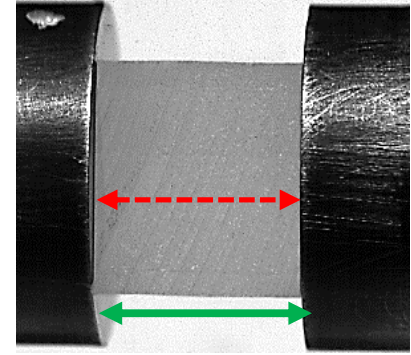

Zone $\mathrm{C}=0.4 \mathrm{~ms}$

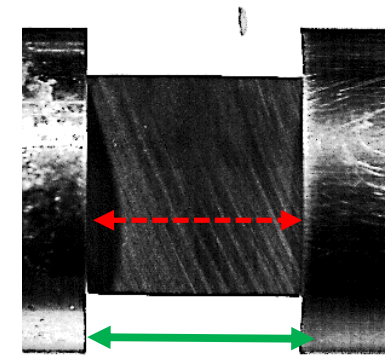

Zone $\mathrm{C}=0.395 \mathrm{~ms}$

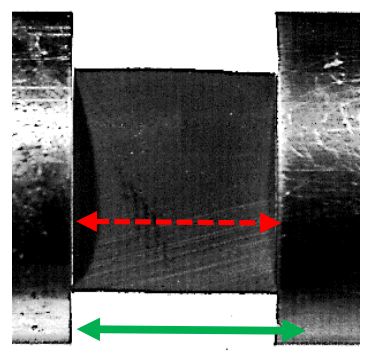

Zone $\mathrm{C}=0.4 \mathrm{~ms}$

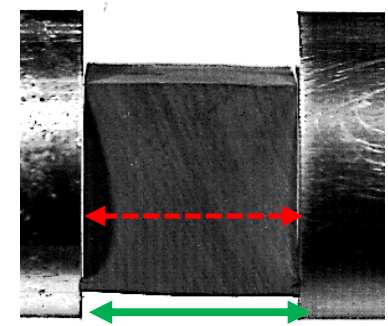

Zone $\mathrm{D}=0.455 \mathrm{~ms}$

Figure 15: High-speed photos of real-time dynamic compression tests of nanocomposites with different graphene mass fractions $(\mathrm{P}=4 \mathrm{bar})$ 


\section{Conclusion:}

In this paper, the influence of GNPs on epoxy polymers was studied. Nanocomposites with 1 wt.\% GNPs showed significant improvement in the mechanical behavior of the epoxy sample under dynamic compression. Further, an increase in the wt.\% of GNPs i.e. 2wt.\% and 5wt.\% showed a reduction in the mechanical performance because of the increase in the viscosity of the matrix which resulted in poor distribution and created agglomeration phenomena. At high GNP percentages, the nanocomposites viscosity rises radically and the air bubble resulted in the porosity creation that has a major consequence on the reduction of the mechanical properties and engenders degradation in the dynamic performance.

\section{References}

[1] G. Chen et al., "Preparation and characterization of graphite nanosheets from ultrasonic powdering technique," Carbon N. Y., vol. 42, no. 4, pp. 753-759, 2004, doi: https://doi.org/10.1016/j.carbon.2003.12.074.

[2] A. Mousa, "The effect of exfoliated graphite on the thermal properties of dynamically vulcanized PS/SBR composites," 2014.

[3] S. Chatterjee, F. Nafezarefi, N. H. Tai, L. Schlagenhauf, F. A. Nüesch, and B. T. T. Chu, "Size and synergy effects of nanofiller hybrids including graphene nanoplatelets and carbon nanotubes in mechanical properties of epoxy composites," Carbon N. Y., vol. 50, no. 15 , pp. 5380-5386, 2012.

[4] M. Tarfaoui, L. Hamitouche, S. Khammassi, and O. Shah, "Examination of the Delamination of a Stitched Laminated Composite with Experimental and Numerical Analysis Using Mode I Interlaminar,” Arab. J. Sci. Eng., 2020, doi: 10.1007/s13369020-04599-z.

[5] A. Jumahat, C. Soutis, J. Mahmud, and N. Ahmad, "Compressive properties of nanoclay/epoxy nanocomposites," Procedia Eng., vol. 41, pp. 1607-1613, 2012.

[6] A. Jumahat, C. Soutis, F. R. Jones, and A. Hodzic, "Fracture mechanisms and failure analysis of carbon fibre/toughened epoxy composites subjected to compressive loading," Compos. Struct., vol. 92, no. 2, pp. 295-305, 2010. 
[7] A. Jumahat, "Effect of nanofillers on thermo-mechanical properties of polymers and composite laminates." University of Sheffield, 2011.

[8] J. Lee and A. F. Yee, "Inorganic particle toughening II: toughening mechanisms of glass bead filled epoxies," Polymer (Guildf)., vol. 42, no. 2, pp. 589-597, 2001.

[9] R. Bagheri and R. A. Pearson, "The use of microvoids to toughen polymers," Polymer (Guildf)., vol. 36, no. 25, pp. 4883-4885, 1995.

[10] L. M. McGrath, R. S. Parnas, S. H. King, J. L. Schroeder, D. A. Fischer, and J. L. Lenhart, "Investigation of the thermal, mechanical, and fracture properties of aluminaepoxy composites," Polymer (Guildf)., vol. 49, no. 4, pp. 999-1014, 2008.

[11] R. A. Pearson and A. F. Yee, "Toughening mechanisms in thermoplastic-modified epoxies: 1. Modification using poly (phenylene oxide)," 1993.

[12] F. Hussain, M. Hojjati, M. Okamoto, and R. E. Gorga, "Polymer-matrix nanocomposites, processing, manufacturing, and application: an overview," J. Compos. Mater., vol. 40, no. 17, pp. 1511-1575, 2006.

[13] S. Sassi, M. Tarfaoui, M. Nachtane, and H. Ben Yahia, "Strain rate effects on the dynamic compressive response and the failure behavior of polyester matrix," Compos. Part B Eng., vol. 174, p. 107040, 2019.

[14] A. El Moumen, M. Tarfaoui, and K. Lafdi, "Computational homogenization of mechanical properties for laminate composites reinforced with thin film made of carbon nanotubes," Appl. Compos. Mater., vol. 25, no. 3, pp. 569-588, 2018.

[15] Y. Qureshi, M. Tarfaoui, and K. Lafdi, "Multi-mode real-time strain monitoring in composites using low vacuum carbon fibers as a strain sensor under different loading conditions," Smart Mater. Struct., 2020.

[16] A. El Moumen, M. Tarfaoui, and K. Lafdi, "Multifunctional composites based carbon nanotubes for marine energy conversion systems," 2017.

[17] O. H. Hassoon, M. Tarfaoui, A. E. M. Alaoui, and A. El Moumen, "Mechanical behavior of composite structures subjected to constant slamming impact velocity: An experimental and numerical investigation," Int. J. Mech. Sci., vol. 144, pp. 618-627, 2018. 
[18] A. Jumahat, C. Soutis, F. R. Jones, and A. Hodzic, "Effect of silica nanoparticles on compressive properties of an epoxy polymer," J. Mater. Sci., vol. 45, no. 21, pp. 5973$5983,2010$.

[19] A. El Moumen, M. Tarfaoui, M. Nachtane, and K. Lafdi, "Carbon nanotubes as a player to improve mechanical shock wave absorption," Compos. Part B Eng., vol. 164, pp. 67$71,2019$.

[20] N. Berhanuddin et al., "Enhancement of mechanical properties of epoxy/graphene nanocomposite," in J Phys Conf Ser IOP Publ, 2017, vol. 12036.

[21] Z. Yu, Z. Wang, H. Li, J. Teng, and L. Xu, "Shape memory epoxy polymer (SMEP) composite mechanical properties enhanced by introducing graphene oxide (GO) into the matrix," Materials (Basel)., vol. 12, no. 7, p. 1107, 2019.

[22] G. I. Giannopoulos and I. G. Kallivokas, "Mechanical properties of graphene based nanocomposites incorporating a hybrid interphase," Finite Elem. Anal. Des., vol. 90, pp. 31-40, 2014.

[23] S. K. Khanna and H. T. T. Phan, "High strain rate behavior of graphene reinforced polyurethane composites," J. Eng. Mater. Technol., vol. 137, no. 2, 2015.

[24] Y.-J. Wan et al., "Improved dispersion and interface in the graphene/epoxy composites via a facile surfactant-assisted process," Compos. Sci. Technol., vol. 82, pp. 60-68, 2013.

[25] J. Wei, R. Atif, T. Vo, and F. Inam, "Graphene nanoplatelets in epoxy system: dispersion, reaggregation, and mechanical properties of nanocomposites," J. Nanomater., vol. 2015, 2015.

[26] M. Tarfaoui, K. Lafdi, I. Beloufa, D. Daloia, and A. Muhsan, "Effect of graphene nanoadditives on the local mechanical behavior of derived polymer nanocomposites," Polymers (Basel)., vol. 10, no. 6, p. 667, 2018.

[27] M. Chihi, M. Tarfaoui, Y. Qureshi, H. Benyahia, and C. Bouraoui, "Graphene nanofillers as a player to improve the dynamic compressive response and failure behavior of carbon/epoxy composite,” Nanotechnology, vol. 31, no. 42, p. 425709, 2020.

[28] A. Manta, M. Gresil, and C. Soutis, "Tensile and flexural behaviour of a graphene/epoxy composite: experiments and simulation,” J. Phys. Mater., vol. 3, no. 1, p. 14006, 2019. 
[29] L.-C. Tang et al., "The effect of graphene dispersion on the mechanical properties of graphene/epoxy composites," Carbon N. Y., vol. 60, pp. 16-27, 2013.

[30] F. Wang, L. T. Drzal, Y. Qin, and Z. Huang, "Mechanical properties and thermal conductivity of graphene nanoplatelet/epoxy composites," J. Mater. Sci., vol. 50, no. 3, pp. 1082-1093, 2015.

[31] Q.-A. Poutrel, Z. Wang, D. Wang, C. Soutis, and M. Gresil, "Effect of pre and postdispersion on electro-thermo-mechanical properties of a graphene enhanced epoxy," Appl. Compos. Mater., vol. 24, no. 2, pp. 313-336, 2017.

[32] C. M. Hadden et al., "Mechanical properties of graphene nanoplatelet/carbon fiber/epoxy hybrid composites: Multiscale modeling and experiments," Carbon N. Y., vol. 95 , pp. 100-112, 2015.

[33] M. Tarfaoui, M. Nachtane, and A. El Moumen, "Energy dissipation of stitched and unstitched woven composite materials during dynamic compression test," Compos. Part B Eng., vol. 167, pp. 487-496, 2019.

[34] M. Tarfaoui and M. Nachtane, "Can a three-dimensional composite really provide better mechanical performance compared to two-dimensional composite under compressive loading?," J. Reinf. Plast. Compos., vol. 38, no. 2, pp. 49-61, 2019.

[35] G. Larbi, T. Mostapha, O. Hocine, and A. E. M. Alaoui, "A practical note for SHPB test with new algorithms for delimiting pulses," Compos. Struct., vol. 126, pp. 145-158, 2015.

[36] U. S. Lindholm, "Some experiments with the split hopkinson pressure bar*," J. Mech. Phys. Solids, vol. 12, no. 5, pp. 317-335, 1964.

[37] O. S. Lee and M. S. Kim, "Dynamic material property characterization by using split Hopkinson pressure bar (SHPB) technique," Nucl. Eng. Des., vol. 226, no. 2, pp. 119$125,2003$.

[38] P. Bailly, F. Delvare, J. Vial, J. L. Hanus, M. Biessy, and D. Picart, "Dynamic behavior of an aggregate material at simultaneous high pressure and strain rate: SHPB triaxial tests," Int. J. Impact Eng., vol. 38, no. 2-3, pp. 73-84, 2011.

[39] M. Tarfaoui, S. Choukri, and A. Nême, "Effect of fibre orientation on mechanical properties of the laminated polymer composites subjected to out-of-plane high strain rate 
compressive loadings," Compos. Sci. Technol., vol. 68, no. 2, pp. 477-485, 2008.

[40] E. Pullicino, W. Zou, M. Gresil, and C. Soutis, "The effect of shear mixing speed and time on the mechanical properties of GNP/epoxy composites," Appl. Compos. Mater., vol. 24, no. 2, pp. 301-311, 2017.

[41] S. Sassi, M. Tarfaoui, and H. Ben Yahia, "An investigation of in-plane dynamic behavior of adhesively-bonded composite joints under dynamic compression at high strain rate," Compos. Struct., vol. 191, pp. 168-179, 2018.

[42] M. Tarfaoui, A. El Moumen, and K. Lafdi, "Progressive damage modeling in carbon fibers/carbon nanotubes reinforced polymer composites," Compos. Part B Eng., vol. 112, pp. 185-195, 2017.

[43] M. Nachtane, M. Tarfaoui, Y. Ledoux, S. Khammassi, E. Leneveu, and J. Pelleter, "Experimental investigation on the dynamic behavior of 3D printed CF-PEKK composite under cyclic uniaxial compression," Compos. Struct., vol. 247, 2020, doi: 10.1016/j.compstruct.2020.112474.

[44] M. Nachtane, M. Tarfaoui, S. Sassi, A. El Moumen, and D. Saifaoui, "An investigation of hygrothermal aging effects on high strain rate behaviour of adhesively bonded composite joints," Compos. Part B Eng., vol. 172, pp. 111-120, 2019.

[45] N. K. Naik, K. S. Pandya, V. R. Kavala, W. Zhang, and N. A. Koratkar, "Alumina nanoparticle filled epoxy resin: High strain rate compressive behavior," Polym. Eng. Sci., vol. 54, no. 12, pp. 2896-2901, 2014.

[46] M. R. Ayatollahi, S. Shadlou, M. M. Shokrieh, and M. Chitsazzadeh, "Effect of multiwalled carbon nanotube aspect ratio on mechanical and electrical properties of epoxybased nanocomposites," Polym. Test., vol. 30, no. 5, pp. 548-556, 2011.

[47] Z. Li and J. Lambros, "Dynamic thermomechanical behavior of fiber reinforced composites," Compos. Part A Appl. Sci. Manuf., vol. 31, no. 6, pp. 537-547, 2000. 